\title{
Peculiarities of Biermer Disease in a Senegalese Internal Medicine Department: A 6 Year Prospective Study
}

Diop Madoky $\mathbf{M}^{1 *}$, Berthe $\mathbf{A}^{1}$, Toure $\mathbf{P S}^{1}$, Ndiaye FSD³ ${ }^{3}$ Mahamat $\mathbf{Y}^{1}$, Leye $\mathbf{M Y}^{2}$, Diousse $\mathbf{P}^{1}$, Adamson $\mathbf{P}^{1}$, Leye $\mathrm{A}^{2}$ and Ka $\mathbf{M M}^{1}$

${ }^{1}$ Department of Internal Medicine Regional Hospital Thies, Faculty of Health Sciences Thies, University of Thiès, Senegal

${ }^{2}$ Department of Internal Medicine, Pikine National Hospital, Ex Camp Militaire de Thiaroye, Sénégal

${ }^{3}$ Medical Clinic number 1, Aristide Le Dantec National Hospital Dakar, Dakar, Senegal

\begin{abstract}
Summary: Biermer's disease also called pernicious anemia (PA) presents certain peculiarities among black patient such as early age diagnosis and a frequent acquired melanodermia without obvious causes like adrenal insufficiency to explain it. The anemia can also be multifactorial.

Patients and Methods: This was a prospective study between May 2007 and June 2013 at the department of internal medicine of the Thies regional hospital, Senegal. All cases that presented with recurrent anemia without gastro intestinal bleeding were recruited. Cases associated with renal disease, tuberculosis, deficiency of acid folic and patients on treatments like amiodarone or alcolisme were excluded from the study.

Results: A number of 28 Patients were retained for the study with a mean age 43 years and the sex ratio $\mathrm{M} / \mathrm{F}$ at 2.1. Average time to diagnosis was 3 years with extreme ages ranging from 2 to 8 years. The diagnosis was suspected in the presence of Neurologic-anemic syndrome and confirmed by low vitamin B12 blood levels and the presence of anti intrinsic factor antibodies. In certain patients, vitamin B12 therapeutic test was contributive. The clinical manifestations were dominated by lower limbs paresthesia in $24(85.71 \%$ of the patients, sensory Ataxia in $3(10.71 \%)$ of the patients, and combined sclerosis of the bone marrow in $1(3.57 \%)$ patient. Glossitis and melanodermia was equally present in $78.57 \%$ of all the cases. Association with beta-thalassemia Plummer Vinson syndrome (SPV) and hyperthyroidism were observed in 1 case. Gastro intestinal hemorrhage was observed in 3 patients among whom one had hemorrhoids specifically the SPV patient. The other 2 cases were diagnosed with bulbar ulcers. Biermer's disease was also was also seen by deep vein thrombosis in 2 cases $(7.14 \%)$ and also by cerebral vascular accident in one patient $(3.57 \%)$. The Anemia was macrocytic in 19 $(67.85 \%)$ of the cases, normocytic in $7(25 \%)$, and microcytic in $2(7.14 \%)$ of the cases. The mean hemoglobin level was at $5.8 \mathrm{~g} / \mathrm{dl}$. Serum vitamin B12 low in $25(89.28 \%)$ of the patients with a mean value at $50 \mathrm{pg} / \mathrm{ml}$. Anti intrinsic factor antibodies were positive in $20(71.24 \%)$ of the cases. In patients who had gastroscopy, the histology showed features of chronic atrophic gastritis in $71.24 \%$ of the cases. The treatment comprised whole blood transfusions and supplementations of iron and vitamin b12 parenterally. In all of our patients, there was regression completely of the melanodermia, glossitis and normalization of the hemoglobin.
\end{abstract}

Conclusion: In our study we note that Biermer's disease in the black patient could present itself by an acquired melanodermia. The anemia could be normo or microcytic depending on other intrinsic causes.

Keywords: Biermer disease; Black; Anemia; Thies; Senegal

\section{Introduction}

Pernicious Anemia (PA) also called Biermer disease is an autoimmune disease which often shows a female predominance [1]. In black patients, occurrence at a younger age with slight male predominance is increasingly being reported. Also, despite skin hyperpigmentation being a classical sign of adrenal insufficiency, an increase of cases with acquired hyperpigmentation without any other explanation was noted in relation of PA [2-4].

Macrocytosis is usually the main biological presenting sign at but others causes of iron deficiency could lead to errors of diagnoses of PA [2,5].

Our aim is to report on cases of PA collected during a period 6 years at the internal medicine department of the Thiès regional hospital, showing unusual aspects of this disease, such as high frequency of skin hyperpigmentation and association with Plummer Vinson syndrome, beta thalassemia or bleeding gastro duodenal ulcer.

\section{Methods and Materials}

We proceeded with the case study which was performed in the Department of Internal Medicine of Regional Hospital of Thies (Senegal) from $1^{\text {st }}$ May 2007 to June $30^{\text {th }} 2013.28$ cases of recurrent anemia were recruited. Patients older than 80 years or those presenting chronic renal failure, leukemia or lymphoma were excluded as well as patients who were followed for tuberculosis or alcoholism. So were patients being treated with amiodarone based medications as well as those with folic acid deficiency.

Pernicious anemia Suspected in the presence of was led by association between chronic anemia, neurological manifestations and a low blood rate of vitamin B12. And, diagnosis was confirmed by the presence of anti-intrinsic factor antibodies or a positive response to systemic vitamin B12 therapy.

*Corresponding author: Madoky Magatte Diop, Department of Health Sciences, Internal Medicine specialist, Thiès Regional Hospital, University of Thies, Senegal, Tel: +221-776355744; E-mail: maxmadoky@hotmail.com

Received September 20, 2013; Accepted November 25, 2013; Published November 28, 2013

Citation: Madoky MD, Berthe A, Toure PS, Mahamat Y, Leye MY, et al (2013) Peculiarities of Biermer Disease in a Senegalese Internal Medicine Department: A 6 Year Prospective Study. J Blood Disorders Transf 5: 179. doi: 10.4172/2155-9864.1000179

Copyright: (c) 2013 Madoky MD, et al. This is an open-access article distributed under the terms of the Creative Commons Attribution License, which permits unrestricted use, distribution, and reproduction in any medium, provided the original author and source are credited. 


\section{Results}

The median age for these 28 cases was 43 years, with extremes ranging from 27 to 80 . The sex ratio in this series was 2.11 (19 men and 9 women). The average time to diagnosis was 3 years (extremes: 2 to 8 ). Major clinical signs of anemia were dyspnea and conjunctiva pallor. 22 (78.57\%) had glossitis associated with hyperpigmentation of the palm of hands.

Gastrointestinal bleeding was noted for three patients who respectively had Kelly-Patterson syndrome (also called Plummer Vinson Syndrome) for the first one and duodenal ulcer for two of them. Vaginal bleeding was noted in another patient who also had beta thalassemia disorder.

Neurological involvement was noted in all cases presenting with paresthesia of the lower limbs in 24 subjects $(85.71 \%)$ or sensorial ataxia in 3 cases $(10.71 \%)$ and sub acute combined spinal cord degeneration in one patient (3.57\%) (Table 1). Biermer's disease also presented with deep venous thrombosis in two patients $(7.14 \%)$ and ischemic stroke in one case (3.57\%). Association of hyperthyroidism, Kelly-Patterson syndrome, beta thalassemia or bleeding gastro duodenal ulcer was respectively noted for 5 patients.

Complete blood count revealed an anemia with a median hemoglobin level at $5.8 \mathrm{~g} / \mathrm{dL}$ (extremes: 2 to 6). Macrocytosis was present in 19 cases (67.85\%) and normocytosis in 7 cases (25\%). Microcytosis was found in two patients (7.14\%) who also had beta thalassemia for the first and Kelly-Patterson syndrome for the second one. Rate of reticulocytes was below $20000 / \mathrm{mm}^{3}$ in all patients.

Vitamin B12 concentration was low in 25 patients with a median value at $50 \mathrm{pg} / \mathrm{mL}$ and positivity of anti-intrinsic factor antibodies was notedin 20 cases (100\%). For the 8 remaining patients, blood assessment of antibodies could not be performed due to financial reasons. However, therapeutic test (systemic administration of vitamin B12) was successful in all of these patients.

Blood rate of homocystein was elevated in only one patient (3.57\%) who also presentedwith DVT. Upper gastrointestinal endoscopy with biopsy was done in 14 patients showing a normal mucosa in 4 cases (28.57\%). And, chronic atrophic gastritis features found in the other 10 patients $(71.42 \%)$. Nevertheless, for 8 of the 14 remaining patients who could not have endoscopy due to intolerance to the procedure, positiveanti-intrinsic factor antibodies were found.

Vitamin B12 (hydroxocobalamin) injections were used for the treatment of all patients. So, within an average time of 15 days, we noted complete regression of the skin hyperpigmentation and of the neurological symptoms, whereas glossitis usually disappeared after one

\begin{tabular}{|l|l|c|c|}
\hline \multicolumn{2}{|l|}{ Clinical characteristics } & $\begin{array}{c}\text { Number of } \\
\text { patients }\end{array}$ & $\%$ \\
\hline Anemia & & 28 & 100 \\
\hline Glossitis & & 22 & 78.57 \\
Melanodermia & 22 & 78.57 \\
\hline Neurology & Lower limbs paresthesia & 24 & 85.71 \\
& Sensorial & 3 & 10.71 \\
& Ataxia & & 3.57 \\
& Sub-acute combined degeneration & 1 & \\
\hline Vascular & of the spinal cord & & 7.14 \\
involvements & DVT* & 2 & 3.57 \\
\hline
\end{tabular}

*DVT: Deep Venous Thrombosis; **IS: Ischemic Stroke

Table 1: Clinical signs found in association with Biermer's disease in our patients. month of treatment. Anticoagulation treatment led to the dissolution of the vascular obstacle for deep venous thrombosis.

\section{Discussion}

Biermers' disease often shows peculiarities in black patients such occurrence at younger age with acquired melanodermia [2-5]. A female predominance is has been reported for this disease [1]. However, a male predominance was found in our cases similar to a previous report by Mukiibi et al. [6]. The median age at presentation was 43 years in our series as other studies concerning black patients which also showed 35 to 42 years at the diagnosis [2,5]. And, our patients were also young compared to average of 75 years found by Girard et al. [7]

Diagnosis of Pernicious anemia was confirmed in our patients in the presence of chronic anemia with neurological manifestations, low blood levels of vitamin B12 and a positive anti-intrinsic factor antibodies test. But as for Segbena et al. [4], positive response to systemic vitamin B12 therapy contributed also to confirmation of PA.

Because of its unusual presentation in black patient, PA could be definitely underestimated $[1,3,6]$. Also, the rare association between Biermer and Plummer-Vinson Syndrome (PVS) or beta-thalassemia [2,5] was found in our series. And, these pathologies often come along with microcytosis related tolow rate of blood iron. Furthermore, PA can in itself be sourcing of iron deficiency by gastric achlorydia which prevent the dissociation of the food iron and its transformation in ferrous iron [8].

Deep venous thrombosis found in three of our 28 patients could be explained by an acquired thrombophilic state related to high blood level of homocystein [9].

The median time to diagnosis was three years in our study, while Mseddi et al. [10] noticed a median delay of 19 years in their work [10]. However, Diop et al. [11] reported a delay of 2 years in a patient with few clinical signs of PA. The revealing events were dominated by chronic anemia associated to lingual inflammation and neurological disorders as for Wun Chan et al. or Diop et al. [11,12].

Paresthesia was mostly found among our patient and it is so described as an important physical sign throughout the literature [13]. Also, in another Senegalese cohort, $42.3 \%$ of patients suffered from peripheral neuropathy [14].

Concerning hyperpigmentation, it leads usually to evoke the diagnosis of Addison's disease [3]. However, despite this clinical sign has been described in PA of black subjects $[5,15,16]$, it is not considered yet as a specific sign of this autoimmune disease. In fact, microscopic examination of the lesions of PA never showed an excess of dermal or epidermal melanin concentrations or infiltration of melanocytes [3]. Nevertheless, complete disappearance of hyperpigmentation following vitamin B12 treatment in case of PA; suggest a role of vitamin B12 in melanin metabolism. This phenomenon could be a consequence of an increase of tyrosine blood concentrations as tyrosine is well known as a melanin precursor and vitamin B12 deficiency has also been described to inhibit liver tyrosine aminotransferase in rats maintained on a vitamin B12-deficient diet [3,16,17].

High prevalence rates of anemia in African series [4,14], could be explained by the delay between first clinical symptoms and the medical consultation. This fact could also be related to a prolonged clinical tolerance associated to lack of technical facilities throughout developing countries [4]. Furthermore, anemia during PA may be multifactorial $[2,5]$. 
Citation: Madoky MD, Berthe A, Toure PS, Mahamat Y, Leye MY, et al. (2013) Peculiarities of Biermer Disease in a Senegalese Internal Medicine Department: A 6 Year Prospective Study. J Blood Disorders Transf 5: 179. doi: 10.4172/2155-9864.1000179

Our study showed, positivity of anti-intrinsic factor antibodies in all cases where it was performed (i.e. 100\%). But despite, their high specificity of PA, these antibodies may be absent among 30 to $50 \%$ of cases [16].

However, Addison's autoimmune disease could not be formally excluded in our series as patients were not systematically checked serum and urinary cortisol concentrations. For the care of all patients, vitamin B12 given by intramuscular way, has led to gradual and complete resolution of clinical and biological disturbances as for Diop et al. [11]

We have not noticed case of death or recurrence of anemia during the current follow-up.

\section{Conclusion}

Biermer's disease often shows unusual presentations among black patients. So, recognition of possible association with an acquired skin hyperpigmentation or other etiologies of iron deficiency could lead to establish early the diagnosis of this autoimmune disease.

\section{References}

1. Savage D, Gangaidzo I, Lindenbaum J, Kiire C, Mukiibi JM, et al. (1994) Vitamin $\mathrm{B} 12$ deficiency is the primary cause of megaloblastic anaemia in Zimbabwe. Br J Haematol 86: 844-850.

2. Diop MM, Toure PS, Leye MY, Leye A, El Fadjri S, et al. (2012) [Unusual aspect of pernicious anemia during association of beta-thalassemia: a new case report and literature review]. Mali Med 27: 71-72.

3. Ben Kacem Ernez S, Ach K, Maaroufi A, Zaouali M, Chaieb MC, et al. (2004) [Hyperpigmentation in pernicious anaemia]. Rev Med Interne 25: 475-476.

4. Segbena AY, Ambofo-Planche Y, Gbadoe AD, Dogba AD, Kueviakoe IM, et al (2003) [Four case reports of Biermer's anemia in West Africa]. Med Trop (Mars) 63: 593-596.

5. Diop MM, Leye MY, Toure PS (2012) Syndrome de Plummer Vinson de découverte fortuite au cours d'une maladie de Biermer, cas et revue de la littérature. Rev Int Sci Med 14: 165-168.
6. Mukiibi JM, Makumbi FA, Paul B, Gwanzura C, Pade JK (1990) Megaloblastic anaemia in Zimbabwe: the pernicious anaemias. East Afr Med J 67: 501-506.

7. Girard D, Jacob P, Damon H, Espinouse D, Cceur P, et al. (1994) [Major pancytopenia in Biermer disease. 5 cases]. Ann Med Interne (Paris) 145: 177-180.

8. Lagarde S, Jovenin N, Diebold MD, Jaussaud R, Cahn V, et al. (2006) Is there any relationship between pernicious anemia and iron deficiency? Gastroenterol Clin Biol 30: 1245-1249.

9. Ammouri W, Tazi MZ, Harmouche H, Aouni M, Adnaoui M (2009) Analyse de quatre observations de thrombose veineuse révélant une maladie de Biermer. Rev Med Int 30: S64

10. Mseddi M, Bouassida S, Marrekchi S, Khemakhem M, Turki H, et al. (2006) [Biermer disease disclosed by mucous ulcerations]. Rev Med Liege 61: 611-613.

11. Diop S, Ka MM, Mbengue M, Dangou JM, Pouye A, et al. (1999) [Biermer's disease without anemia: apropos of 2 cases manifested as glossitis with macrocytosis]. Dakar Med 44: 134-136.

12. Wun Chan JC, Yu Liu HS, Sang Kho BC, Yin Sim JP, Hang Lau TK, et al. (2006) Pernicious anemia in Chinese: a study of 181 patients in a Hong Kong hospital. Medicine (Baltimore) 85: 129-138.

13. Maamar M, Tazi-Mezalek Z, Harmouche H, Ammouri W, Zahlane M, et al. (2006) [Neurological manifestations of vitamin B12 deficiency: a retrospective study of 26 cases]. Rev Med Interne 27: 442-447.

14. Ndiaye FSD, Diouf ML, Fall S, Souhaibou N, Mamadou MK, et al. (2006) Maladie de Biermer révélée par une hépatite à Epstein - Barr virus. Hématologie 12: $357-359$

15. Iba Ba J, Bignoumba IR, Moussavu B, Coniquet S, Boguikouma JB, et al (2008) Mélanodermie et maladie de Biermer chez le noir Africain : A propos de trois observations. Louvain Medical 127: 344-349.

16. Ebara S, Nakao M, Tomoda M, Coniquet S, Boguikouma JB, et al. (2008) Vitamin B12 deficiency results in the abnormal regulation of serine dehydratase and tyrosine aminotransferase activities correlated with impairment of the adenylyl cyclase system in rat liver. Br J Nutr 99: 503-510.

17. Kaltenbach G, Andrès E, Barnier-Figue G, Noblet-Dick M, Noël E, et al. (2005) [Low vitamin B12 levels in elderly patients cured within one week by ora cobalamin therapy]. Presse Med 34: 358-362.
Citation: Madoky MD, Berthe A, Toure PS, Mahamat Y, Leye MY, et al. (2013) Peculiarities of Biermer Disease in a Senegalese Internal Medicine Department: A 6 Year Prospective Study. J Blood Disorders Transf 5: 179 doi: 10.4172/2155-9864.1000179 